\title{
The Prevalence of Rare Variants Potentially Important for the Response to Medicines Used for CVD Treatment in the Lithuanian Population
}

Pranculis $A^{1^{*}}$, Rančelis $T^{1}$, Ambrozaitytè $L^{1}$, Uktverytè $\mathrm{I}^{1}$, Domarkienè $\mathrm{I}^{1}$, Burokienè $\mathrm{N}^{2}$, Kučinskienè $Z A^{3}$ and Kučinskas $V^{1}$

${ }^{1}$ Department of Human and Medical Genetics, Faculty of Medicine, Vilnius University, Lithuania

${ }^{2}$ Clinic of Internal Diseases Family Medicine and Oncology, Faculty of Medicine, Vilnius University, Lithuania

${ }^{3}$ Department of Physiology, Biochemistry, Microbiology and Laboratory Medicine Faculty of Medicine, Vilnius University, Lithuania

*Corresponding author: Aidas Pranculis, Department of Human and Medical Genetics, Faculty of Medicine, Vilnius University, Lithuania, Tel: +370 5 2501798; E-mail: aidas.pranculis@mf.vu.It

Received date: March 14, 2016; Accepted date: April 18, 2016; Published date: April 25, 2016

Copyright: $(2016$ Pranculis A, et al. This is an open-access article distributed under the terms of the Creative Commons Attribution License, which permits unrestricted use, distribution, and reproduction in any medium, provided the original author and source are credited.

Abstract
Cardiovascular disease (CVD) is one of the leading causes of death among Europeans and around the world.
Major factors that are considered relevant for the efficacy or adverse drug reactions (ADRs) caused by drugs used
for CVD treatment have been identified through GWAS studies mostly using low density common variant genotyping
arrays.
In this study whole exome sequencing (WES) was carried out to identify genomic variants relevant for CVD
treatment. The study group included 98 ( 49 males and 49 females) self-reported healthy unrelated individuals from
the Lithuanian population with at least three generations of Lithuanian ethnicity and residency in the same ethno-
linguistic region. After performing WES genetic loci of 55 genes that were reported as relevant to the efficacy or
ADRs caused by drugs used for CVD treatment were analyzed using LifeScope
The and ANNOVAR software.
splice site variant that may affect the efficacy or cause ADRs in patients treated for CVD. Over 400 potentially
relevant SNVs in different frequencies were detected in the genes reported to be important for CVD treatment. The
strength of evidence analysis identified 14 SNVs most likely to be relevant for CVD treatment. The frequency
distribution of several variant alleles that have been shown to be highly important for CVD treatment in the CYP2D6
(rs16947) and ADRB1 (rs1801253) as well as several variants in the CYP2C9 and NAT2 genes were determined to
be significantly (p<0.05) different from other Caucasian populations showing the potential benefit of
pharmacogenomic testing prior to treatment in the Lithuanian population. The research was carried out under the
LITGEN project. LITGEN project (VP1-3.1-ŠMM-07-K-01-013) was funded by the European Social Fund under the
Global Grant measure.

Keywords Indels; Coronary heart disease; ANNOVA; CVD treatment

\section{Introduction}

Cardiovascular diseases (CVD) remain the leading cause of death among Europeans and around the world. The Global Burden of Disease study estimated that $29.6 \%$ of all deaths worldwide (15.6 million deaths) were caused by CVD in 2010, more than all communicable, maternal, neonatal and nutritional disorders combined, and double the number of deaths caused by cancers [1].

Although the number of diagnosed cases of CVD and coronary heart disease (CHD) in particular has been constantly rising there is clear evidence in most countries with available data that mortality and case-fatality rates from $\mathrm{CHD}$ and stroke have decreased substantially over the last 5-10 years but at differing rates. The number of CVD caused death cases has fallen quite substantially in western European countries while several Eastern European countries including Russia, Ukraine and Lithuania have shown little evidence of such trends [2].

These trends indicate that the possible reason for the contrasting changes in CVD caused hospitalizations and CVD caused deaths may be attributed to the advances made in healthcare quality associated with medicine based treatment and risk factor management. Pharmacogenomics based CVD drug prescription may help further reduce the number of CVD caused deaths and reduce adverse drug reactions which have been reported about 5 times more frequently in Lithuania between the years of 2007 and 2015 [3].

There is significant inter individual variability in the response to pharmacologic agents used for CVD treatment [4]. Plasma drug levels can differ by orders of magnitude when the same drug dose is administered to two patients who are similar in age and weight [5]. Many environmental factors can influence the variability in drug responses between patients including drug-drug interactions, concomitant diseases and ethnicity, however, genetic factors are also highly likely to play a major role especially in the case of non-inducible enzymes like $C Y P 2 D 6$ [6].

The aim of this study was to investigate the pharmacogenomic peculiarities of the Lithuanian population by analyzing the distribution patterns of allele and genotype frequencies of common and rare variants in the genes associated with drug efficacy and adverse drug reactions (ADR). 
Citation: Pranculis A, Rancelis T, Ambrozaityte L, Uktveryte I, Domarkiene I, et al. (2016) The Prevalence of Rare Variants Potentially Important for the Response to Medicines Used for CVD Treatment in the Lithuanian Population. J Pharmacogenomics Pharmacoproteomics 7: 157. doi: $10.4172 / 2153-0645.1000157$

Page 2 of 6

\section{Methods}

\section{Study group}

The study group included 98 (49 males and 49 females) selfreported healthy unrelated individuals from the Lithuanian population with at least 3 generations living in Lithuania. The individuals included in the study group adequately represent the Lithuanian population as the group includes individuals from all six Lithuanian ethnolinguistic groups (Figure 1).

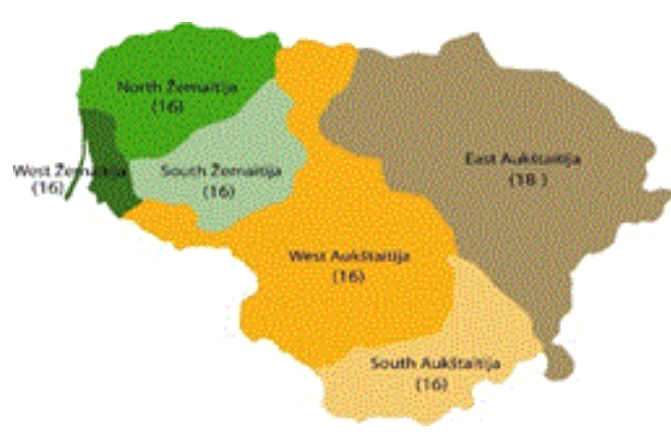

Figure 1: Number of individuals from each ethnolinguistic group of Lithuania.

\section{Genomic marker selection}

The most commonly used drugs for the treatment of CVD belong to the classes of non-steroid anti-inflammatory agents (NSAID), ACE inhibitors, $\beta$-blockers, antithrombotic and antiplatelet agents, statins and others. Genes were chosen for the analysis in this study based on the strength of evidence associating drugs belonging to these classes with genetic factors that affect their efficacy or risk of ADRs. The frequency of use of the drugs from these drug classes in the Lithuanian population was also taken into consideration. The selected genes are presented in Table 1.

\begin{tabular}{|l|l|l|l|}
\hline Gene & Drug class & Gene & Drug class \\
\hline$A B C B 1$ & $\begin{array}{l}\text { Antithrombotics, } \\
\text { Antiarrhythmics, Diuretics, } \\
\text { Statins }\end{array}$ & HTR3B & Statins \\
\hline$A B C C 2$ & Antithrombotics, Statins & HTR7 & Statins \\
\hline$A C E$ & ACE inhibitors, Statins & ITGB3 & Antithrombotics \\
\hline $\begin{array}{l}\text { ADAMTS } \\
1\end{array}$ & Statins & $K C N E 1$ & Antiarrhythmics \\
\hline$A D R B 1$ & $\beta$-blockers & $K C N E 2$ & Antiarrhythmics \\
\hline$A D R B 2$ & $\beta$-blockers & $K C N H 2$ & Antiarrhythmics \\
\hline$A G T$ & ACE inhibitors & $K C N J 2$ & Antiarrhythmics \\
\hline$A K A P 9$ & Antiarrhythmics & $K C N Q 1$ & Antiarrhythmics \\
\hline$A P O E$ & Statins & $K I F 6$ & Statins \\
\hline$B C H E$ & Vasodilators & $L P L$ & Statins \\
\hline$B D K R B 1$ & ACE inhibitors & LTC4S & NSAIDs \\
\hline
\end{tabular}

\begin{tabular}{|c|c|c|c|}
\hline$B D K R B 2$ & ACE inhibitors & MTHFR & Statins \\
\hline CBS & Statins & NOS3 & Vasodilators, $\beta$-blockers \\
\hline CETP & Statins & NAT1 & $\begin{array}{l}\text { Vasodilators, } \\
\text { Antiarrhythmics }\end{array}$ \\
\hline $\begin{array}{l}\text { CYP11B } \\
2\end{array}$ & $\begin{array}{l}\text { Vasodilators, diuretics, } \beta \text { - } \\
\text { blockers }\end{array}$ & NAT2 & NSAIDs, Antiarrhythmics \\
\hline CYP1A2 & Antiarrhythmics & $N P C 1 L 1$ & Statins \\
\hline $\begin{array}{l}\text { CYP2C1 } \\
9\end{array}$ & $\begin{array}{l}\beta \text {-blockers, Antithrombotics, } \\
\text { Statins }\end{array}$ & $P 2 R Y 1$ & NSAIDs, Antithrombotics \\
\hline CYP2C8 & NSAIDs, Antiarrhythmics & P2RY12 & NSAIDs, Antithrombotics \\
\hline CYP2C9 & $\begin{array}{l}\text { NSAIDs, } \quad \beta \text {-blockers, } \\
\text { Antithrombotics, Statins }\end{array}$ & PON1 & Antithrombotics \\
\hline CYP2D6 & $\beta$-blockers, Antiarrhythmics & PTGS1 & NSAIDs, Antithrombotics \\
\hline CYP3A4 & Statins, Antiarrhythmics & PTGS2 & NSAIDs, Antithrombotics \\
\hline $\begin{array}{l}\text { CYP3A4 } \\
3\end{array}$ & Statins & SCN5A & Antiarrhythmics \\
\hline CYP3A5 & Statins, Antithrombotics & $\begin{array}{l}S L C O 1 B \\
1\end{array}$ & Statins \\
\hline CYP4F2 & Antithrombotics & SNTA1 & Antiarrhythmics \\
\hline FCAR & Statins & UGT1A1 & Statins \\
\hline GNB3 & Diuretics & $\begin{array}{l}\text { VKORC } \\
1\end{array}$ & Antithrombotics \\
\hline GRK5 & Vasodilators, $\beta$-blockers & $\begin{array}{l}\text { XPNPEP } \\
2\end{array}$ & ACE inhibitors \\
\hline HMGCR & Statins & & \\
\hline
\end{tabular}

Table 1: Pharmacogenomically relevant genes and associated drug classes.

\section{Whole exome sequencing}

For the analysis of SNVs and small indels the whole exome sequencing (WES) method was employed using the Applied Biosystems 5500 SOLiD $^{\text {mw }}$ Sequencer with the Agilent SureSelectXT Target Enrichment System and Life Technologies TargetSeq ${ }^{\text {"m }}$ Exome Enrichment System without Exact Call Chemistry (ECC). During the experiment the protocols supplied by the kit providers were optimized and used [7]. Using either exome sequencing system important variants may be found outside of the targeted exonic regions [8]. Therefore, all identified variants with sufficient coverage and quality scores were included in the analysis. Over $80 \%$ of identified variants in the selected genes identified in this study have already been described and included in public databases including dbSNP, 1000 Genome and Exome Aggregation Consortium (ExAC) datasets. The frequencies of indels and identified SNV alleles were also compared to the Caucasian populations included in the mentioned datasets.

\section{Bioinformatics and statistical analysis}

Primary analysis of image acquisition and bead processing, application of quality metrics and color calls were performed within the SOLiD sequencer. Secondary and tertiary exome sequencing data analyses were carried out using Life Technologies ${ }^{\mathrm{TM}}$ proprietary 
Citation: Pranculis A, Rancelis T, Ambrozaityte L, Uktveryte I, Domarkiene I, et al. (2016) The Prevalence of Rare Variants Potentially Important for the Response to Medicines Used for CVD Treatment in the Lithuanian Population. J Pharmacogenomics Pharmacoproteomics 7: 157. doi: $10.4172 / 2153-0645.1000157$

Page 3 of 6

LifeScope $^{\mathrm{TM}}$ 2.5.1 genomic analysis software. Standard analysis workflow of the exome data was carried out in three stages using targeted.resequencing.frag workflow with default parameters set [9]. Variants with coverage of more than 10x were used to filter out the less reliable calls [10]. Minimum read mapping quality value of 8 was used. A minimum allele ratio of 0.15 was used for a heterozygous genotype call. A color minimum quality value of 7 was used for a candidate allele to be called as SOLiD system uses color space coding.

ANNOVAR software was used to annotate the exome sequencing data and identify variants likely to be relevant for CVD treatment [11]. Chi-square test and where appropriate Fishers exact test were used to compare allele and genotype frequency distributions between populations and datasets with the significance threshold considered to be at $\mathrm{p}<0.05$.

\section{Results and Discussion}

\section{Small insertion and deletion analysis}

Most of the indel variants identified in this study were previously unreported in literature or the analyzed datasets. They also were present in the Lithuanian population at a low frequency.

\begin{tabular}{|l|l|l|l|l|l|l|l|l|}
\hline Chr & Start Pos & End Pos & Gene & Ref & Alt & $\begin{array}{l}\text { 1000g EUR } \\
\text { Alt }\end{array}$ & ExACEur Alt & LTU Alt \\
\hline 3 & 38622618 & 38622618 & SCN5A & G & - & - & - & 0,005 \\
\hline 6 & 39507972 & 39507973 & KIF6 & TT & - & - & - & 0,005 \\
\hline 7 & 87195476 & 87195476 & ABCB1 & A & - & - & - & 0,005 \\
\hline 7 & 99273810 & 99273810 & CYP3A5 & - & C & 0,012 & 0,011 & 0,005 \\
\hline 7 & 99434078 & 99434078 & CYP3A43 & A & - & 0,038 & 0,037 & 0,036 \\
\hline 8 & 18258073 & 18258073 & NAT2 & - & A & - & - & 0,010 \\
\hline 9 & 125145847 & 125145847 & PTGS1 & C & - & - & - & 0,005 \\
\hline 10 & 101552021 & 101552021 & ABCC2 & G & - & - & - & 0,005 \\
\hline 10 & 101577212 & 101577212 & ABCC2 & G & - & - & - & 0,005 \\
\hline 10 & 115804365 & 115804365 & ADRB1 & - & T & - & - & 0,005 \\
\hline 12 & 21391965 & 21391969 & SLCO1B1 & TATAT & - & - & $7,71 \mathrm{E}-05$ & 0,005 \\
\hline 19 & 16000503 & 16000503 & CYP4F2 & C & - & - & $1,50 E-05$ & 0,010 \\
\hline 22 & 42524339 & 42524339 & CYP2D6 & A & - & - & - & 0,005 \\
\hline
\end{tabular}

Table 2: Frequencies of exonic frameshift Indels potentially relevant for drug metabolism.

Using the default LifeScope ${ }^{\mathrm{TM}}$ software parameters 31,623 unique short indels were called in the study group from the Lithuanian population over 70 of which we called in the pharmacogenomically relevant genes. 13 of the called variants were identified as exonic frameshift variants (3 insertions and 10 deletions) (Table 2). Only two of the called variants were previously identified and included in the dbSNP142 database - CYP3A43 rs61469810 (c.74delA) and CYP3A5 rs200579169 (c.92dupG). Neither of these variants has been previously reported to be associated with the efficacy or ADRs caused by drugs metabolized by $C Y P 3 A 43$ and $C Y P 3 A 5$.

The CYP3A43 rs61469810 variant deletion allele was reported $10.5 \%$ of the cases in the total 1000 genome dataset and $5.4 \%$ in the ExAC dataset while it was found at a frequency of $3.8 \%$ in the 1000 genome European dataset and $3.7 \%$ in the ExAC NFE dataset. The data in Lithuanian population was in concordance with the datasets of European individuals. In the Lithuanian study group, a single individual was identified as heterozygous for the rs61469810 deletion allele and 3 individuals were homozygous for the deletion allele (deletion allele frequency 3,6\%). The CYP3A5 rs200579169 variant insertion allele was identified in a single heterozygous individual representing a lower frequency $(0.05 \%)$ than identified in the 1000 genome European and ExAC NFE datasets $(1.2 \%$ and $1.1 \%$ respectively).

A single exonic non-frameshift insertion in $A K A P 9$ gene (c. 4003_4004insAAC, rs10644111) was identified. 34 individuals were heterozygous and 8 individuals were homozygous for these variants. The $25.5 \%$ insertion allele frequency was significantly lower than the frequencies reported in both total and European origin 1000 Genome datasets $(42.4 \%$ and $38.7 \%$ respectively, $\mathrm{p}<0.001)$. It was also significantly lower compared to the frequencies in both total and nonFinnish European ExAC (ExAC NFE) datasets (both at 40, 1\%, $\mathrm{p}<0.0001)$.

The analysis of indels in the introns of pharmacogenomically relevant genes revealed further 53 variants (39 deletions and 14 insertions) one of which (not found in dbSNP) was identified as a splice site mutation in the GRK5 gene g.121086027delG.

The identified indels that were included in dbSNP 1000 Genomes and the ExAC datasets were not previously associated with efficacy of CVD treatment drugs or ADRs caused by them, yet in a relatively small population sample $20 \%$ of subjects had at least one exonic indel variant in clinically actionable genes identified by Clinical 
Citation: Pranculis A, Rancelis T, Ambrozaityte L, Uktveryte I, Domarkiene I, et al. (2016) The Prevalence of Rare Variants Potentially Important for the Response to Medicines Used for CVD Treatment in the Lithuanian Population. J Pharmacogenomics Pharmacoproteomics 7: 157. doi:10.4172/2153-0645.1000157

Page 4 of 6

Pharmacogenetics Implementation Consortium (CPIC) and included in the PharmGKB database showing the value of the non-candidate gene approach [12].

\section{Single nucleotide variant analysis}

In the 98 individuals from the Lithuanian population a total of 243,192 unique SNVs were called. Over 300 unique SNVs were called in the exons of the genes potentially important for CVD treatment. 184 variants in the exons were called as non-synonymous SNVs and 148 synonymous SNVs. Further 385 SNVs were identified in the introns, 28 in 3' UTR and 11 in 5' UTR region. Of the total 775 identified variants 631 were included in the dbSNP142 database. Of the identified exonic variants $256 \mathrm{SNV}$ s were identified and included in the dbSNP142 database.

Of the identified 256 exonic SNVs 156 had the variant allele frequency of $<1 \%$ and were not included in further frequency analysis. Of these variants 86 were included in the dbSNP142 dataset. The analysis of allele frequencies of these variants showed no significant differences between Lithuanian population and study groups of European descent included in the 1000 Genomes and ExAC datasets. With the only exception of the CYP11B2 rs4539 (c.518A >G) which had significantly higher $G$ allele frequency $(p<0,0001)$ in the EUR group of the 1000 Genome dataset (48.4\%) and ExAC NFE dataset (45.2\%) compared to the Lithuanian population $(1,2 \%)$.

\begin{tabular}{|c|c|c|c|c|c|c|c|}
\hline Chr & Gene & SNV & $\begin{array}{l}\operatorname{Re} \\
f\end{array}$ & $\begin{array}{l}\text { Al } \\
t\end{array}$ & $\begin{array}{l}1000 \mathrm{~g} \text { EUR } \\
\text { Alt }\end{array}$ & $\begin{array}{l}\text { ExAC EUR } \\
\text { Alt }\end{array}$ & LTU Alt \\
\hline chr8 & NAT2 & $\begin{array}{l}\text { rs180128 } \\
0\end{array}$ & T & C & 0.449 & 0.456 & 0.423 \\
\hline chr8 & NAT2 & $\begin{array}{l}\text { rs179993 } \\
0\end{array}$ & G & A & 0.282 & 0.290 & 0.224 \\
\hline chr8 & NAT2 & rs1208 & G & A & 0.562 & 0.567 & 0.526 \\
\hline chr8 & NAT2 & $\begin{array}{l}\text { rs } 179993 \\
1\end{array}$ & G & A & 0.023 & 0.025 & 0.061 \\
\hline $\begin{array}{l}\text { chr1 } \\
0\end{array}$ & $A D R B 1$ & $\begin{array}{l}\text { rs180125 } \\
3\end{array}$ & G & C & 0.685 & 0.722 & 0.102 \\
\hline $\begin{array}{l}\text { chr1 } \\
0\end{array}$ & $\begin{array}{l}\text { CYP2C } \\
19\end{array}$ & $\begin{array}{l}\text { rs283995 } \\
04\end{array}$ & A & G & 0.001 & 0.003 & 0.005 \\
\hline $\begin{array}{l}\text { chr1 } \\
0\end{array}$ & $\begin{array}{l}\text { CYP2C } \\
19\end{array}$ & $\begin{array}{l}\text { rs } 424428 \\
5\end{array}$ & G & A & 0.145 & 0.148 & 0.138 \\
\hline $\begin{array}{l}\text { chr1 } \\
0\end{array}$ & $\begin{array}{l}\text { CYP2C } \\
9\end{array}$ & $\begin{array}{l}\text { rs179985 } \\
3\end{array}$ & C & $T$ & 0.124 & 0.127 & 0.066 \\
\hline $\begin{array}{l}\text { chr1 } \\
0\end{array}$ & $\begin{array}{l}\text { CYP2C } \\
9\end{array}$ & $\begin{array}{l}\text { rs105791 } \\
0\end{array}$ & A & C & 0.073 & 0.069 & 0.051 \\
\hline $\begin{array}{l}\text { chr2 } \\
2\end{array}$ & $\begin{array}{l}\text { CYP2D } \\
6\end{array}$ & $\begin{array}{l}\text { rs113584 } \\
0\end{array}$ & G & C & 0.454 & 0.448 & 0.383 \\
\hline $\begin{array}{l}\text { chr2 } \\
2\end{array}$ & $\begin{array}{l}\text { CYP2D } \\
6\end{array}$ & rs 16947 & A & G & 0.657 & 0.657 & 0.541 \\
\hline $\begin{array}{l}\text { chr2 } \\
2\end{array}$ & $\begin{array}{l}\text { CYP2D } \\
6\end{array}$ & $\begin{array}{l}\text { rs } 106585 \\
2\end{array}$ & G & A & 0.202 & 0.249 & 0.143 \\
\hline $\begin{array}{l}\text { chr1 } \\
6\end{array}$ & $\begin{array}{l}\text { VKORC } \\
1\end{array}$ & $\begin{array}{l}\text { rs993443 } \\
8\end{array}$ & G & A & 0.388 & NA & 0.087 \\
\hline
\end{tabular}

Table 3: Frequencies of SNVs identified in the ClinVar database as associated with drug response.
Variants in the CYP11B2 (rs1799998) gene have been previously associated with Arterial hypertension and treatment of arterial hypertension with diuretics like furosemide, $\beta$-blockers like atenolol and others $[13,14]$. Using the ClinVar database which reports the relationships among human variations and phenotypes based on supporting evidence 13 variants in the analyzed exomes were identified as related to drug response (Table 3) [15].

\section{Arylamine N-acetyltransferase 2 (NAT2) gene}

High level of variation was identified in the NAT2 gene. The gene codes for an Arylamine $\mathrm{N}$-acetyltransferases (NAT) which are xenobiotic metabolizing enzymes. NAT2 expression is found predominantly in the liver, small intestine and colon tissues and thus is regarded as a typical xenobiotic metabolizing enzyme, though basal NAT2 mRNA levels can be found in most tissues [16,17]. Humans exhibit genetic polymorphism in NAT2 resulting in rapid, intermediate and slow acetylator phenotypes. Over $65 N A T 2$ variants possessing one or more SNPs in the 870-bp NAT2 coding region have been reported. Of the seven most frequent SNPs rs1801279 (c.191G>A), rs1041983 (c. $282 \mathrm{C}>\mathrm{T}$ ), rs1801280 (c.341T>C), rs1799929 (c.481C>T), rs1799930 (c. $590 \mathrm{G}>\mathrm{A}), \mathrm{rs} 1208(\mathrm{c} .803 \mathrm{~A}>\mathrm{G})$ and $\mathrm{rs} 1799931$ (c.857G $>\mathrm{A})$ we identified rs1801280, rs1208, rs1799930 and rs1799931 which allows the inference of acetylator status with over $92 \%$ accuracy [18].

rs 1801280 (c. $341 \mathrm{~T}>\mathrm{C}$ ) which is a signature SNP for $N A T 2{ }^{*}$ allelic group which was shown in over 30 publications to confer a slow acetylation phenotype [19]. Based on the rs 1801280 polymorphism the frequency of the $N A T 2^{*} 5$ allele in the Lithuanian population is $42.3 \%$ which is lower, but not significantly different from 1000 Genomes and ExAC datasets.

The rs1208 $\mathrm{G}$ allele is present in a range of allelic NAT2 variants most notably ${ }^{\star} 4$ (wildtype) and ${ }^{*} 12$ which are associated with rapid acetylator status, yet the rs 1208 allele $\mathrm{G}$ is present in multiple $N A T 2^{*}$ alleles that confer different phenotypes, thus separately it does not provide sufficient information to attribute acelylator status to the subject and therefore coverage of the other SNPs in these alleles is required.

rs1799930 (c.590G>A, p.Arg197Gln) is the signature SNP for the $N A T 2^{*} 6$ allelic group. ${ }^{*} 6 A$ is a common allele, with a global frequency of $26 \%$, ranging from $13 \%$ in Baka Pygmies, $22 \%$ in Koreans, $27 \%$ in US Caucasians, and $32 \%$ in Russians [20]. In the Lithuanian population the frequency of the A allele is found at a frequency of $22.4 \%$ which is significantly less frequent than in 1000 Genome and ExAC datasets of European descent (28.2\% and 29\% respectively).

The rs1799931 (c.857G $>$ A, p.Gly286Glu) is the signature SNP for $N A T 2^{*} 7$ allelic group. ${ }^{*} 7 A$ and ${ }^{*} 7 B$ confer a slow acetylator phenotype but this may be dependent on substrate. This variant is often grouped with other variants that confer a slow acetylation phenotype. rs1799931 allele $\mathrm{A}$ is the only variant of the $N A T 2^{*} 7 A$ allele, which should only be defined if other positions have been examined and confirmed to be wildtype by genotyping. The rs1799931 allele A is rare in Caucasian populations as represented by frequencies of $2.5 \%$ in the 1000 Genomes dataset and $2.5 \%$ in the ExAC dataset. The allele was identified significantly more often in the Lithuanian population at $6.1 \%$.

None of the individually genotyped variants are sufficient to identify specific NAT2 alleles, yet their ability to predict allelic groups show that the prevalence of rare acetylator status in the Lithuanian 
Citation: Pranculis A, Rancelis T, Ambrozaityte L, Uktveryte I, Domarkiene I, et al. (2016) The Prevalence of Rare Variants Potentially Important for the Response to Medicines Used for CVD Treatment in the Lithuanian Population. J Pharmacogenomics Pharmacoproteomics 7: 157. doi:10.4172/2153-0645.1000157

Page 5 of 6

population is significantly less common than in other populations of European descent identified in the 1000 Genomes and ExAC datasets.

\section{The cytochrome $\mathbf{P 4 5 0}$ superfamily genes}

SNV rs28399504 (c.1A>G) in the CYP2C19 gene the alternate G allele of which is strongly associated with decreased response to a popular antiplatelet agent Clopidogrel and is present in the $C Y P 2 C 19^{*} 4, C Y P 2 C 19^{*} 4, C Y P 2 C 19^{*} 4 A, C Y P 2 C 19^{*} 4 B$ haplotypes was identified at a frequency $0.5 \%$ in the Lithuanian population which is higher than the frequencies reported in the 1000 Genomes and ExAC datasets (both at $0.1 \%$ ) [21]. The A allele of the CYP2C19 rs4244285 (c. $681 \mathrm{G}>\mathrm{A}$ ) SNV was less common in the Lithuanian population compared to the same datasets. The presence of this allele may decrease the possibility of treatment with Clopidogrel being ineffective, yet no statistical significance was achieved when comparing the allele frequency distributions [22].

The cytochrome P450 2D6 (CYP2D6) is an enzyme highly important for pharmacogenomics and is now thought to be involved in the metabolism of up to $25 \%$ of commonly used drugs [23]. CYP2D6 polymorphisms have implications across many different therapeutic areas, as a diverse array of clinically used drugs are metabolized by CYP2D6 including antiarrhythmics (Flecainide, Mexiletine, Propafenone) and beta-blockers (Carvedilol, Metoprolol, Timolol) [24]. Depending on the activity of the CYP2D6 enzyme subjects can be divided in order of highest functioning to lowest: ultrarapid metabolizers (UM), extensive metabolizers (EM), intermediate metabolizers (IM), and poor metabolizers (PM) [24]. In the literature CYP2D6 allele frequencies are usually reported in terms of haplotypes. The separate variants interrogated in this study by themselves or in combination with each other are not sufficient for the identification of specific haplotypes as $\mathrm{rs} 1135840$ (c.1304G $>\mathrm{C}$ ) C allele is present in over 50 different CYP2D6 haplotypes and rs16947 (c.T733C) in over 40 , but as the variant $\mathrm{T}$ allele of the rs $1065852(\mathrm{c} .100 \mathrm{C}>\mathrm{T})$ is present in both the non-functional $C Y P 2 D 6^{*} 4$ haplotype and the reduced function $C Y P 2 D 6^{*} 10$ haplotypes it is important to note that $\mathrm{T}$ allele is less common $(14.3 \%)$ in the Lithuanian population compared to the reference datasets (1000Genomes and ExAC) used for this study ( $20.2 \%$ and $24.9 \%$ respectively).

$C Y P 2 C 9$ is a phase I drug-metabolizing cytochrome $\mathrm{P} 450$ ( $C Y P 450)$ enzyme that plays a major role in the oxidation of both xenobiotic and endogenous compounds. CYP2C9 is the enzyme responsible for the metabolism of the S-isomer of warfarin that is the key isoform responsible for the anticoagulant effect of the drug.

Patients with the poor metabolizer ${ }^{*} 2$ (rs1799853. c. 430C $\left.>\mathrm{T}\right)$ and ${ }^{*} 3$ (identified by rs1057910. c.1075A $>$ C) haplotypes require lower doses of warfarin to achieve a similar anticoagulant as patients with at least one ${ }^{*} 1$ (wild-type) haplotype $[25,26]$. CYP2C 9 genotype accounts for only part of the variability in Warfarin efficacy as VKORC1 genotype as well as phenotypes including age and weight are also key factors in predicting the therapeutic dose for warfarin $[27,28]$. Both variants associated with the decreased CYP2C9 activity phenotypes were identified in the study. rs $1057910 \mathrm{C}$ allele in the Lithuanian population was found at a lower frequency $(5.1 \%)$ then in the chosen reference datasets - 1000 genomes (7.3\%) and ExAC (6.9\%), but statistical significance was not achieved ( $p>0.05$ ) while the rs1799853 T allele significantly less common in the Lithuanian study group $-6.6 \% \mathrm{vs}$ $12.4 \%$ and $12.7 \%$ respectively ( $\mathrm{p}$ values 0.017 and 0.011 respectively).

\section{Genes important for drug pharmacodynamics}

rs9934438 (g.1173C > T) is a SNP in the first intron of VKORC1 gene and is in near perfect linkage disequilibrium with rs9923231. rs9934438 was the first SNP associated with the low dose warfarin requirement [29]. Although it is considered to have no functional effect, rs9934438 is commonly used to infer rs9923231 genotype and haplotypes containing this variant. $\mathrm{T}$ allele is associated with response to a lower warfarin dose and as this allele is significantly common in the Lithuanian population (8.7\%) compared to European descent subgroup of the 1000 Genomes dataset (the SNP was not identified in the ExAC dataset). It is thus reasonable to assume that it is likely that a patient from the Lithuanian population treated with warfarin will require a lower dose to achieve a therapeutic affect and are at a higher risk of adverse bleeding reactions when treated with regular warfarin dose than patients from other Caucasian populations especially considering the low frequency of the $C Y P 2 C 9{ }^{*} 2$ and ${ }^{*} 3$ alleles in the Lithuanian population.

The rs1801253 (c.1165G>C, p.Gly389Arg) variant in the ADRB1 gene has been shown in multiple studies to be important for the treatment of hypertension, CHD and other CVDs [30]. The rs1801253 polymorphism is located in the cytoplasmic tail in the G-protein coupling domain [31]. In vitro studies of the c.1165G $>C$ variant indicate that basal and agonist-simulated adenylyl cyclase activity is higher with the $\mathrm{C}$ allele present as a result of enhanced coupling to Gs [32]. Significant associations have been shown of the rs1801253 alleles and the efficacy of various drugs including $\beta$-blockers: carvedilol, metoprolol, Dobutamine, atenolol and others including ACE inhibitors and diuretics $[33,34]$. The $\mathrm{C}$ allele which is associated with decreased response to atenolol, carvedilol, diltiazem, metoprolol or verapamil is significantly less common in the Lithuanian population $(10.2 \%)$ compared to 1000 Genomes and ExAC project European subsets ( $68.5 \%$ and $72.2 \%$ respectively, $p<0,0001$ in both cases) indicating that in the Lithuanian population a lack of response to treatment with a range $\beta$-blockers may be less likely than in other compared Caucasian populations [35].

\section{Conclusion}

Exome sequencing approach to testing the prevalence of pharmacogenomically relevant variants in a population proved effective as a range of different types of variants at varying frequencies was identified in the study group from the Lithuanian population. Using conservative quality control criteria to preserve specificity the applied method revealed over 300 exonic variants (13 indels and 300 SNVs) in the genes relevant for cardiovascular disease treatment. Every subject from the studied 98 individuals had at least 2 variants that could be relevant for CVD treatment. Given the number of different types of medications used to treat common CVDs like CHD the number of identified variants is significant. While a large number of exonic variants that were identified in the pharmacogenomically relevant genes in this study have not been previously associated with efficacy or ADRs caused by specific CVD drugs, the amino acid changes caused by the variants as well as protein function prediction (SIFT, PolyPhen) and conservation (PhyloP) scores indicate the potential relevance which should be investigated in further functional studies [36]. Furthermore, the used method provided sufficient coverage of intronic regions and UTRs to identify variants that were shown to affect the efficacy or ADRs caused by drugs used for CVD treatment thus further showing the utility of the approach. 
Citation: Pranculis A, Rancelis T, Ambrozaityte L, Uktveryte I, Domarkiene I, et al. (2016) The Prevalence of Rare Variants Potentially Important for the Response to Medicines Used for CVD Treatment in the Lithuanian Population. J Pharmacogenomics Pharmacoproteomics 7: 157. doi:10.4172/2153-0645.1000157

Page 6 of 6

The in-depth analysis of both exome small indels and SNVs shows that several pharmacogenomically relevant variants are found in the Lithuanian population that distinguish it from other populations of European descent. Some of the identified variants in NAT2, CYP2C9 and $V K O R C 1$ genes in particular make a case for the move towards genetic testing in clinical practice as standard phenotype based drug dose attributions may not only fail to achieve a required therapeutic effect but cause adverse drug reactions.

\section{References}

1. Lozano R, Naghavi M, Foremen K, Lim S, Shibuya K, et al. (2012) Globa and regional mortality from 235 causes of death for 20 age groups in 1990 and 2010: a systematic analysis for the Global Burden of Disease Study 2010. Lancet 380: 2095-2128.

2. Nichols M, Townsend N, Scarborough P, Rayner M (2014) Cardiovascular disease in Europe 2014: epidemiological update. Eur Heart J 35: 2950-2959.

3. Kudelienè S (2015) Received reports of adverse reactions report.

4. Maitland-van der Zee AH, de Boer A, Leufkens HG (2000) The interface between pharmacoepidemiology and pharmacogenetics. Eur J Pharmacol 410: 121-130.

5. Ingelman-Sundberg M (2001) Pharmacogenetics: an opportunity for a safer and more efficient pharmacotherapy. J Intern Med 250: 186-200.

6. Teh LK, Bertilsson L (2012) Pharmacogenomics of CYP2D6: molecular genetics, interethnic differences and clinical importance. Drug Metab Pharmacokinet 27: 55-67.

7. Fragment Library preparation 5500 series SOLiD systems. Applied Biosystems.

8. Guo Y, Long J, He J, Li C, Cai Q, et al. (2012) Exome sequencing generates high quality data in non-target regions. BMC Genomics 13: 194.

9. Biosystems A (2012) LifeScope ${ }^{\mathrm{Tm}}$ Genomic Analysis Software 2.5.1 Command Shell Data Analysis and Interpretations.

10. Casals F, Hodgkinson A, Hussin J, Idaghdour Y, Bruat V, et al. (2013) Whole-exome sequencing reveals a rapid change in the frequency of rare functional variants in a founding population of humans. PLoS Genet 9 : 1003815 .

11. Wang K, Li M, Hakonarson H (2010) ANNOVAR: functional annotation of genetic variants from high-throughput sequencing data. Nucleic Acids Res 38: 164 .

12. https://www.pharmgkb.org

13. Kurland L, Liliedahl U, Karlsson J, Kahan T, Malmqvist K, et al. (2004) Angiotensinogen gene polymorphisms: relationship to blood pressure response to antihypertensive treatment. Results from the Swedish Irbesartan Left Ventricular Hypertrophy Investigation vs Atenolol (SILVHIA) trial. Am J Hypertens 17: 8-13.

14. Yang YY, Lin HC, Lin MW, Chu CJ, Lee FY, et al. Identification of diuretic non-responders with poor long-term clinical outcomes: a 1-year followup of 176 non-azotaemic cirrhotic patients with moderate ascites. Clin Sci (Lond), 121: 509-521.

15. Landrum MJ, Lee JM, Riley GR, Jang W, Rubinstein WS, et al. (2014) ClinVar: public archive of relationships among sequence variation and human phenotype. Nucleic Acids Res 42: 980-985.

16. Hein DW (2009) N-acetyltransferase SNPs: emerging concepts serve as a paradigm for understanding complexities of personalized medicine. Expert Opin Drug Metab Toxicol 5: 353-66.

17. Husain A, Zhang X, Doll MA, States JC, Barker DF et al. (2007) Identification of $\mathrm{N}$-acetyltransferase 2 (NAT2) transcription start sites and quantitation of NAT2-specific mRNA in human tissues. Drug Metab Dispos 35: 721-727.

18. Hein DW, Doll MA, (2012) Accuracy of various human NAT2 SNP genotyping panels to infer rapid, intermediate and slow acetylator phenotypes. Pharmacogenomics 13: 31-41.
19. McDonagh EM, Boukouvala S, Aklillu E, Hein DW, Altman RB, et al. (2014) PharmGKB summary: very important pharmacogene information for N-acetyltransferase 2. Pharmacogenet Genomics 24: 409-425.

20. Sabbagh A, Langaney A, Darlu P, Gerard N, Krishnamoorthy R, et al. (2008) Worldwide distribution of NAT2 diversity: implications for NAT2 evolutionary history. BMC Genet 9: 21.

21. Collet JP, Hulot JS, Cuisset T, Range G, Cayla G et al. (2015) Genetic and platelet function testing of antiplatelet therapy for percutaneous coronary intervention: the ARCTIC-GENE study. Eur J Clin Pharmacol 71: 1315-1324.

22. Cui H, Lin S, Chen X, Gao W, Li X, et al. (2015) Correlation Between SNPS in Candidate Genes and VerifyNow-Detected Platelet Responsiveness to Aspirin and Clopidogrel Treatment. Cardiovasc Drugs Ther 29: 137-46.

23. Ingelman-Sundberg M, Sim SC, Gomez A, Rodriquez-Antona C (2007) Influence of cytochrome P450 polymorphisms on drug therapies: pharmacogenetic, pharmacoepigenetic and clinical aspects. Pharmacol Ther 116: 496-526.

24. Gardiner SJ, Begg EJ (2006) Pharmacogenetics, drug-metabolizing enzymes, and clinical practice. Pharmacol Rev 58: 521-590.

25. Aithal GP, Day CP, Kesteven PJ, Daly AK (1999) Association of polymorphisms in the cytochrome P450 CYP2C9 with warfarin dose requirement and risk of bleeding complications. Lancet 353: 717-719.

26. Lindh JD, Holm L, Andersonn ML, Rane A (2009) Influence of CYP2C9 genotype on warfarin dose requirements--a systematic review and metaanalysis. Eur J Clin Pharmacol 65: 365-375.

27. Tabrizi AR, Zehnbauer BA, Borecki IB, McGrath SD, BuchmanTG, et al. (2002) The frequency and effects of cytochrome P450 (CYP) 2 C9 polymorphisms in patients receiving warfarin. J Am Coll Surg 194: 267-273.

28. Takahashi H, Wilkinson GR, Nutescu EA, Morita T, Ritchie MD, et al. (2006) Different contributions of polymorphisms in VKORC1 and $C Y P 2 C 9$ to intra- and inter-population differences in maintenance dose of warfarin in Japanese, Caucasians and African-Americans. Pharmacogenet Genomics 16: 101-110.

29. D'Andrea G, D'Ambrosio RL, Di Perna P, Chetta M, Santacroce R, et al. (2005) A polymorphism in the VKORC1 gene is associated with an interindividual variability in the dose-anticoagulant effect of warfarin. Blood 105: 645-649.

30. Pacanowski MA, Johnson JA, PharmGKB submission update: IX. ADRB1 gene summary. Pharmacol Rev 59 : 2-4

31. Mason DA, Moore JD, Green SA, Liggett SB (1999) A gain-of-function polymorphism in a G-protein coupling domain of the human beta1adrenergic receptor. J Biol Chem 274: 12670-12674.

32. Rathz DA, Gregory KN, Fang Y, Brown KM, Liggett SB, et al. (2003) Hierarchy of polymorphic variation and desensitization permutations relative to beta 1 - and beta 2 -adrenergic receptor signaling. J Biol Chem 278: 10784-10789.

33. Baudhuin LM, Miller WL, Train L, Bryant S, Hartman KA, et al. (2010) Relation of $A D R B 1, C Y P 2 D 6$, and $U G T 1 A 1$ polymorphisms with dose of, and response to, carvedilol or metoprolol therapy in patients with chronic heart failure. Am J Cardiol 106(3): 402-408.

34. Lobmeyer MT, Gong Y, Terra SG, Beitelshees AL, Langaee TY et al. (2007) Synergistic polymorphisms of betal and alpha2C-adrenergic receptors and the influence on left ventricular ejection fraction response to beta-blocker therapy in heart failure. Pharmacogenet Genomics 17: 277-282.

35. Parvez B, Chopra N, Rowan S, Vaglio JC, Muhammad R, et al. (2012) A common betal-adrenergic receptor polymorphism predicts favorable response to rate-control therapy in atrial fibrillation. J Am Coll Cardiol 59: 49-56.

36. Wu J, Jiang $\mathrm{R}$, Prediction of deleterious nonsynonymous singlenucleotide polymorphism for human diseases. ScientificWorldJournal 2013:675851. 